\title{
Estudo lexical dos nomes indígenas das regiões de Aquidauana, Corumbá e Miranda no Estado de Mato Grosso do Sul: a toponímia rural
}

\author{
A lexical study of indigenous names in Aquidauana, Corumbá and \\ Miranda regions of Mato Grosso do Sul: rural toponymy \\ Lucimara Alves da Conceição COSTA* \\ Universidade Estadual Paulista Júlio de Mesquita Filho (UNESP) \\ Vitória Regina SPANGHERO** \\ Universidade Federal de Mato Grosso do Sul (UFMS)
}

\begin{abstract}
RESUMO: Neste trabalho propõe-se um estudo lexical dos nomes de origem indígena que configuram a toponímia rural das regiões de Aquidauana, Corumbá e Miranda pertencentes à mesorregião dos Pantanais Sul-Mato-Grossense. Inicialmente, nossa pesquisa foi realizada por meio de cartas topográficas na escala 1: 125.000 e Mapas Rurais estatísticos (MRU), disponibilizados pelo site do Instituto Brasileiro de Geografia e Estatística (IBGE), criados no ano de 2007. Como método classificatório toponímico, recorremos ao modelo taxionômico proposto por Dick (1990), no qual são apresentadas 27 categorias, divididas em 11 taxes de natureza física e de 16 taxes de natureza antropocultural. Procuramos, por meio da análise semântica dos termos selecionados, definir, apresentar a classificação, taxonomia e etimologia dos topônimos indígenas presentes no processo de nomeação dos acidentes físicos e humanos existentes na zona rural das regiões supracitadas.
\end{abstract}

PALAVRAS-CHAVE: Léxico. Toponímia. Língua indígena.

ABSTRACT: The objective of this work is to carry out a lexical study of names from indigenous origin that configure the Rural Toponymy from Aquidauana, Corumbá and Miranda's regions, which belong to medium-region from Pantanal, Mato Grosso do Sul. Firstly, our research was carried out though topographic letters in scale 1: 125,000 and statistic rural maps, supplied by IBGE (Brazilian Institute of Geography and Statistic) web site, created in 2007. To the toponymic classificatory method, we ran over to the taxonomic model suggested by Dick (1990), which 27 categories are presented, that are divided in 11 taxis of physic nature and 16 taxis of anthropocultural nature. Through the semantic analysis we tried to define and show up classification, taxonomy and etymology of the indigenous toponyms that are present in the nomination process of the human and physical accidents existent in the rural area of the regions mentioned.

KEYWORDS: Lexicon. Toponymy. Indigenous language.

\footnotetext{
* Doutoranda em Linguística, Programa de Pós-Graduação em Estudos Linguísticos da Universidade Estadual Paulista (UNESP), campus de São José do Rio Preto. São José do Rio Preto - SP - Brasil. Email: lucimara.costa@ hotmail.com.

** Doutorado em Linguística; docente da Universidade Federal de Mato Grosso do Sul (UFMS), campus de Três Lagoas. Três Lagoas - MS - Brasil. Email: vspanghero@gmail.com.
} 


\section{Introdução}

Ao atentarmos para a prática da nomeação é necessário, antes de tudo, considerar que esse processo se constitui na relação entre ambiente, cultura e vida de um povo. Dick (1990, p. 5) ressalta que a nomeação dos lugares é uma prática exercida pelo homem desde os primeiros tempos alcançados pela memória humana, uma vez que essa simples ação proporcionava ao homem não apenas um maior contato com o acidente nomeado, mas também uma inegável relação de posse. Como exemplo desse ato designativo, Dick aponta a Bíblia, que traz em seus livros uma coletânea de nomes de lugares ligados a seus possuidores por uma relação histórica e cultural. No Brasil, nesse constante processo de nomeação, surgiram ruas com nomes de personalidades históricas, rios relacionados a nomes de animais ou vegetais e cidades relacionadas a etnias indígenas, entre outros.

A curiosidade humana e a constante evolução científica levaram o homem a refletir sobre esse sistema de designação, transformando em objeto de estudo esse processo tão comum e ao mesmo tempo ignorado. Foi então que surgiu a Toponímia, criada primeiramente na Europa, mais particularmente na França, com o objetivo de estudar os topônimos dos acidentes físicos e humanos de uma região.

A proposta de nossa pesquisa é realizar um estudo lexical dos nomes de origem indígena, que configuram a toponímia rural dos municípios de Aquidauana, Corumbá e Miranda, que fazem parte da mesorregião dos Pantanais Sul-Mato-Grossense. Buscamos ressaltar, por meio do estudo desses topônimos, a importância da influência dos povos indígenas no processo de nomeação dos acidentes físicos e humanos, especialmente os do Estado de Mato Grosso do Sul, que abriga um grande número de povos indígenas, além de destacara efetiva participação desses indígenas no processo de povoamento do Estado.

\section{Léxico, língua e cultura}

Refletir sobre a relação entre léxico, língua e cultura é aceitar que, ao exercer o ato da comunicação, o ser humano se apropria de muito mais que um simples acervo lexical. É por meio do processo de interação propiciado pela linguagem que o homem exterioriza suas crenças, cultura e relação com o meio, esse último visto não apenas como os fatos ambientais, mas também com os fatos históricos e sociais. Segundo Biderman (2001, p. 32), "movido por estímulos exteriores e interiores, o indivíduo é levado a comunicar-se, utilizando o instrumento coletivo de comunicação e expressão: a língua". Dessa forma, a língua funciona como a ferramenta essencial para a interação entre o homem e o mundo.

Para Basílio (2009, p. 9), a língua é de certa forma, um sistema de classificação e de comunicação, pois, conforme aponta a autora, antes de comunicar precisamos, primeiramente, identificar, caracterizar e classificar as coisas de que desejamos falar. Sendo assim, o papel do léxico relaciona-se diretamente a essa dupla função da língua, uma vez que:

[...] o léxico é uma espécie de banco de dados previamente classificados, um depósito de elementos de designação [...]. O léxico, portanto, categoriza as coisas sobre as quais queremos nos comunicar, fornecendo as unidades de designação, as palavras, que utilizamos na construção de enunciados (BASÍLIO, 2009, p. 9).

De acordo com Carvalho (2009, p. 19), o léxico traz no seu âmago o significado de vocabulário, enquanto depositário das palavras de uma língua, que são utilizadas em situação de identificação e comunicação em uma dada comunidade. Assim, consoante a autora: 
[...] léxico (do grego lexicon), em sentido lato, é sinônimo de vocabulário. É o inventário completo dos vocábulos que constam sempre em dicionários de uma língua. Sendo a menos sistemática das estruturas lingüísticas, o léxico depende, em grande parte, da realidade exterior, não linguística. É ainda um conjunto virtual, onde se pode identificar como unidade básica o morfema, ou unidade significativa mínima (CARVALHO, 2009, p. 19).

Seguindo esse raciocínio, nos reportamos a Vilela (1997, p. 31), que acrescenta que o léxico seria uma forma de codificar a realidade extralinguística, de modo a facilitar e propiciar o ato da comunicação, pois

[...] o léxico é, numa perspectiva cognitivo-representativa, a codificação da realidade extralinguística interiorizada no saber de uma dada comunidade linguística. Ou, numa perspectiva comunicativa, é o conjunto das palavras por meio das quais os membros de uma dada comunidade linguística comunicam-se entre si. Tanto na perspectiva da cognição-representação como na perspectiva comunicativa, trata-se sempre da codificação de um saber partilhado [sharedknowledge] (VILELA, 1997, p. 31).

Sapir (1969) ressalta que léxico e cultura relacionam-se diretamente, uma vez que é na língua que se reflete o ambiente físico e social de um povo. Nesse sentido, "o léxico completo de uma língua pode se considerar, na verdade, como o completo inventário de todas as ideias, interesses e ocupações que açambarcam a atenção da comunidade" (SAPIR, 1969, p. 45). Segundo o autor, isso se fundamenta, em especial, quando tratamos das línguas indígenas, acrescentando que se houvesse à nossa disposição um tesouro assim cabal da língua de um dado povo, poderíamos aí inferir, em grande parte, o caráter do ambiente físico e as características culturais do povo considerado. Não é difícil encontrar exemplos de línguas cujo léxico traz assim o sinete do ambiente físico em que se acham situados os seus falantes.

Para Biderman (2001), o léxico relaciona-se ao processo de percepção da realidade, pois é a forma mais usual de o ser humano registrar seu conhecimento sobre o universo, visto que, ao nomear os seres e objetos que o cercam, o homem os classifica e ao mesmo tempo os identifica e caracteriza simultaneamente. Segundo a autora, a partir do momento em que passou a perceber as semelhanças e diferenças entre esses seres e discriminar os traços distintivos que permitem a identificação e individualização desses objetos, o homem começou a estruturar a mundo que o circunda e, nesse processo de nomeação, deu origem ao léxico das línguas naturais. $\mathrm{O}$ ato nomeativo propicia, pois, ao indivíduo uma melhor apropriação e reflexão da realidade.

A respeito desse processo, Solis Fonseca (1997, p. 22) considera que "o topônimo é o meio que o homem emprega para humanizar a paisagem como parte de sua relação com seu ambiente geográfico. Colocar nomes é um meio de introduzir uma ordem humana à paisagem"1. Dessa forma, acreditamos que esse processo designativo e a necessidade de melhor refletir sobre ele foi o que impulsionou o surgimento da Toponímia como ciência.

\footnotetext{
1،Un nombre toponímico es un medio que utiliza el hombre para humanizar el paisaje como parte de su relación con su ambiente geográfico. Poner nombres es parte de un proceso de introducir un orden humano en el paisaje" (SOLIS FONSECA, 1997, p. 22).
} 


\title{
2 O processo de povoamento de Mato Grosso do Sul: a presença indígena
}

O processo de povoamento no Estado de Mato Grosso do Sul iniciou-se no século XVI com a chegada dos europeus. A princípio essa área foi dominada pelos espanhóis, que fundaram um pequeno povoado com o nome de Santiago de Xerez (OLIVEIRA 1999, apud TAVARES, 2004, p. 55). Nessa época, segundo palavras de Gressler et al (2008, p.16) "entre os nativos do território sul-mato-grossense, os mais numerosos [...] eram os Guaranis. Excelentes agricultores plantavam principalmente milho e mandioca".

Em relatos históricos, a presença das bandeiras paulistas é registrada ainda no século XVII. Foi nesse período que os colonizadores espanhóis e portugueses intensificaram ainda mais suas buscas aos índios guaranis para que os mesmos trabalhassem nas atividades agrícolas e de mineração.

Em decorrência da descoberta de ouro na região de Cuiabá começam a surgir as primeiras povoações nas proximidades da cidade, cujo objetivo era defender a fronteira entre o território brasileiro e as terras paraguaias. Assim, os desbravadores empreendiam suas buscas às jazidas de ouro nas imediações de Cuiabá, percorrendo para isso o sul do então Estado de Mato Grosso. Corrêa Filho (1946, p. 139) ressalta que a causa principal do povoamento de Mato Grosso foi a "[...] existência de minerais preciosos, no rico solo, logo ao abrir-se a história da sua vida social, iniciada pelos andejos bandeirantes, que as pepitas de ouro de coxipó converteram em mineradores".

Mediante esse processo de garimpagem, no ano de 1830 já se registrava a presença dos primeiros aglomerados humanos, que mais tarde se converteram no atual estado de Mato Grosso do Sul. Nesse período encontravam-se moradores nos arredores do Forte, ou presídio de Miranda, no Forte Coimbra, nos povoados de Albuquerque, na fazenda Camapuã ${ }^{2}$, no destacamento de Piquiri e no sertão de Garcias (CAMPESTRINI; GUIMARÃES, 2002).

Também tiveram participação ativa nesse processo de povoamento as monções que tinham o rio Tietê como eixo principal em suas expedições (GRESSLER; SWENSSON, 1988 , p. 11). No decorrer dessas viagens, os monçoeiros enfrentavam diversas dificuldades como a velocidade das correntezas, galhos de árvores frondosas que dificultavam a navegação, inúmeras cachoeiras e corredeiras, além dos constantes ataques indígenas. Holanda (2000, p. 94-95), ao referir-se aos paiaguás e depois aos guaicurus, faz a seguinte observação:

\begin{abstract}
Dizem as crônicas que, até 1725, ninguém sabia ao certo que índios eram estes, tão destros na arte de navegar, nem onde habitavam nem que nome tinham. Os Guaicurus, ao contrário, eram antigos conhecedores dos bandeirantes. Os paulistas que primeiro penetraram os sertões de Vacaria encontraram-nos de posse de cavalgadura e de armas de procedência européia, como terçados e facões. As planuras que habitavam, os instintos predatórios que os caracterizavam e sua vida ambulatória os deviam ter predisposto, de longa data, ao uso do cavalo, introduzido pelos espanhóis [...]Longe de ter tornado personagem intrusa e supérflua, o cavalo deveria coordenar-se a semelhante sociedade, como órgão de uma função necessária (HOLANDA, 2000, p. 94-95).
\end{abstract}

\footnotetext{
${ }^{2}$ A fazenda Camapuã foi um dos primeiros núcleos de povoamento da região de Mato Grosso do Sul. Surgiu por volta de 1720 e tornou-se ponto de parada obrigatória para os monçoeiros que partiam em busca da captura de indígenas para a exploração de metais preciosos.
} 
Durante esse período de aprisionamento dos indígenas e na busca constante pelas jazidas de ouro, houve um grande enfraquecimento da etnia guarani, o que possibilitou a entrada de outros povos indígenas como os aruak e os guaicurus na região sul do Pantanal. Os aruak hoje são representados pelos índios terenas, enquanto os guaicurus estão reduzidos a menos de mil índios guaná ou kadiwéu (GRESSLER et al., 2008, p.16).

Os indígenas tentaram resistir bravamente à dominação europeia, mas o resultado foi o quase extermínio dessa população. Uma prova disso é a grande redução no número de línguas indígenas faladas no Brasil. Conforme o apontamento de Seki (2000, p. 238):

\begin{abstract}
Atualmente 180 línguas indígenas são faladas no Brasil. De fato, não há absoluta certeza quanto ao número, o que se deve às dificuldades inerentes à definição técnica do que seja propriamente uma língua (em relação a dialeto, formas antigas e modernas etc.), agravadas pela carência ainda existente de informações sobre as línguas e seus falantes. Estima-se que, no decorrer dos500 anos de colonização, cerca de mil línguas se perderam devido ao desaparecimento físico dos falantes, em decorrência de epidemias, extermínio direto, escravização, redução de territórios, destruição das condições de sobrevivência e aculturação forçada, entre outros fatores que sempre acompanharam as frentes de expansão desde o período colonial até nossos dias. Um exemplo atual é o caso de avanço sobre a área Terra do Sol, em Roraima, habitada pelos grupos indígenas makuxi, wapixana, ingarikó e taurepang. A extensão da perda pode ser claramente visualizada através da localização atual de grupos e línguas indígenas: estão concentrados nas regiões Amazônica e Centro-Oeste, nos Estados do Amazonas, Pará, Rondônia, Roraima, Acre, Maranhão, Mato Grosso, Mato Grosso do Sul, Goiás e Tocantins e, em menor proporção, em outros Estados, tendo desaparecido na prática totalidade da região Leste, de Norte a Sul do País, e mesmo em parte da Amazônia (SEKI, 2000, p. 238).
\end{abstract}

A respeito disso, Rodrigues $(2005$, p. 2) ressalta que pode haver uma margem de erro tanto para mais quanto para menos na contagem apresentada, em decorrência da imprecisão da distinção entre línguas e dialetos. Ainda segundo o autor, nesse número ainda podem constar duas ou três línguas que deixaram de ser faladas, nos últimos cinco anos, porém continuam nos registros do Departamento de Índios Isolados da FUNAI; o autor também admite que dentre os povos ainda sem contato com a nossa sociedade pode haver idiomas ainda não conhecidos.

Consoante Gressler et al. (2008), a maior concentração da população indígena brasileira encontra-se hoje na região amazônica, onde, segundo dados do IBGE apresentados em 2000, vivem cerca de 200 mil indígenas, seguida pelo Mato Grosso do Sul, estado onde vivem cerca de 54 mil indígenas, morando em aldeias ou mesmo fora delas.

A respeito dessa população indígena, as autoras destacam que "os únicos indígenas que têm título de posse de suas terras são os Kadiwéus, da Reserva de Bodoquena, área de 373.024 hectares localizada no antigo município de Corumbá”. De acordo com as autoras, essa área foi doada pelo imperador Dom Pedro II como forma de recompensa pela participação desses indígenas na Guerra do Paraguai.

\title{
3 Apresentação e análise dos dados
}

Apresentamos, no trabalho original, um conjunto de 195 topônimos indígenas e híbridos (indígena-português) referentes aos termos que designam a toponímia rural das regiões de Aquidauana, Corumbá e Miranda, no estado de Mato Grosso do Sul.

Em nossa análise, procuramos priorizar as informações referentes ao significado e à etimologia dos topônimos. Para tanto, elencamos as acepções apresentadas nas seguintes 
obras: Taunay (1875), Sampaio (1901), Mendes (1942), Dias (1970), Barbosa (1970), Khathib (1972), Cruz (1979), Tibiriçá (1984), Cunha (1982), Tibiriçá (1989), Guasch e Ortiz (1996), Tibiriçá (1997), Francisco e Francisco (1997), Cunha (1998), Houaiss e Vilar (2001), Griffths (2002), Borba (2002), Ferreira (2004), Borba et al (2004), Greiser (2007) e Assis (2008).

Mesmo não sendo nosso objetivo proceder a um estudo morfológico dos topônimos destacados, fizemos uma análise introdutória sobre a formação desses termos, tendo em vista que muitos são provenientes do tupi. De fato, segundo Rodrigues (1951, p. 3), "um dos aspectos [...] mais importantes para quem quiser se dedicar à investigação etimológica é, sem dúvida, o processo de composição nesta língua predominantemente incorporante. De igual importância é a derivação por meio de afixos".

Outro aspecto bastante recorrente em nossos dados são os termos híbridos, formados em sua maioria por bases indígenas e afixos originados do português. Assim, recorremos a suportes teóricos pertinentes à morfologia para fundamentar o processo de formação dos termos apresentados na análise.

De acordo com Basílio (2000, p. 84), "o caso mais comum [...] de processo morfológico a serviço da função expressiva da linguagem é o caso de diminutivos, aumentativos e superlativos". Segundo a autora, tanto o diminutivo quanto o aumentativo, além de indicarem uma proporção maior ou menor em relação àquilo que é considerado como um padrão normal, podem expressar também uma atitude emocional do falante em relação ao tamanho do objeto a que se refere.

No caso dos termos híbridos com sufixos diminutivos, o grau representa uma dimensão menor do que o normal, por isso o grau diminutivo é, em geral, definido como diminuição concreta de tamanho, mas também apresenta abrangência maior, indicando diminuição avaliativa ou depreciação (BASÍLIO, 2009, p. 70).

Para Basílio, o principal elemento formador de diminutivos em português é o sufixo -inho, que se alterna com -Zinho quando a forma base termina em consoante, ditongo ou vogal acentuada, entretanto, se, por um lado, -inho e -Zinho parecem ser complementares, uma vez que o segundo deles é utilizado em ambientes fonológicos em que o primeiro não ocorre, a autora ressalta que essa restrição não é absoluta.

A respeito dessa formação, Costa $(2002$, p. 126) aponta que "o sufixo diminutivo apresenta estas duas formas alternantes e que o uso de uma ou outra é condicionado pela sequência de segmentos que constituem a última sílaba da base e pela tonicidade desta mesma sílaba". Dessa forma, de acordo com a autora, a forma -inho ocorre em palavras formadas a partir de bases terminadas em vogais tônicas, em consoantes e em ditongos. Destaca, porém, que a regularidade dessa distribuição não é total, podendo ter a ocorrência de -Zinho no mesmo contexto. A respeito disso, Cunha e Cintra (1985, p. 91) destacam que, "com exceção das palavras terminadas em $-s$ e $-z$, que exigem a forma -inho, não é fácil determinar os motivos que justificam a escolha entre essas duas formas". Os autores apontam, contudo, certa predisposição da norma culta para a utilização de formações com -Zinho e não -inho-, o que, segundo eles, decorre da intenção de preservar a pronúncia da unidade lexical da qual a nova palavra derivou.

Como exemplos de topônimos híbridos formados por sufixos diminutivos, encontramos em nosso corpus os nomes: mangabinha, taboquinha e taquaretinha, aguassuzinho, baguaçuzinho, buritizinho, cambarazinho, caraguazinho, carandazinho, sucurizinho, taquaralzinho e tarumãzinho, formados pela junção de radicais indígenas tupi/guaranis e sufixos da língua portuguesa.

Como exemplo de topônimo híbrido com sufixo aumentativo, temos, em nossos dados, o nome pindaivão, formado pelo acréscimo do sufixo aumentativo -ão. 
Sobre este tipo de formação, Rio-Torto (1998, p. 161) destaca que "abundam em português os nomes sufixados em -ao derivados de bases nominais. De acordo com a autora, a operação semântica associada à regra que os gera pode ser definida como uma operação de intensidade ou de aumento de alguma ou de algumas das propriedades designadas pela base.

Destacamos, porém, que a formação dos topônimos híbridos de maior ocorrência em nosso corpus foi a que se refere aos locativos. Segundo Rio-Torto (1998, p. 176), “o estatuto morfoderivacional dos diferentes tipos de locativos do português só pode ser explicado à luz da estrutura morfológica e semântica dos nomes que lhes servem de base e mediante o conhecimento da identidade estrutural e da própria história do sufixo em jogo". De acordo com a autora, por nomes de lugar entendem-se diferentes categorias e produtos nominais. Como exemplo disso, temos "os nomes que designam lugares, que integram, albergam ou que são preenchidos por grande quantidade do número de base" (RIOTORTO, 1998, p. 179).

No caso de nossos dados, temos os topônimos: acurizal, angical, bacaiuval, buritizal, cambarazal, carandazal, guanandizal, indaial, mangabal, pindaival, pirizal,piuval, sucupiral, tabocal e taquaral, topônimos híbridos formados pela junção tupi/guarani/português.

Outro exemplo de locativo é o caso do topônimo pitangueira, "locativo não deverbal que designa local/objeto continente de número de base; local/objeto/receptáculo [...]; local ou objeto onde se guarda, existe ou [...] está depositado o número de base" (RIO-TORTO, 1998, p. 182).

A respeito dessa formação, Basílio (2009, p. 75) aponta que, no caso do uso do sufixo -eiro/a com agentes vegetais, "incluem-se as plantas, sobretudo árvores, denominadas a partir de seu produto (fruta, flor, etc.)".

Outro caso de termo híbrido encontrado em nossos dados é o topônimo "cipolândia", cujo sufixo (-lândia) é geralmente utilizado como pospositivo em referência a locativos pátrios (terra, país, região), porém acreditamos que, ao ser utilizado com o designativo cipó, perdeu essa característica de locativo e passou a ser empregado como ideia de coletividade.

A propósito da motivação toponímica dos designativos destacados, procuramos evidenciar, especialmente, a relação homem, ambiente e linguagem no ato da nomeação. Para isso, recorremos, em parte, a aspectos históricos. Destacamos, porém, que nossos dados foram analisados numa perspectiva sincrônica e não diacrônica.

\section{Discussão dos resultados da pesquisa}

\subsection{Quanto à natureza}

Quanto à natureza dos topônimos, verificamos o predomínio dos nomes de natureza física em detrimento dos topônimos de natureza antropocultural.

A predominância de elementos de natureza física se justifica pela relação de proximidade e mesmo de cumplicidade entre o indígena e o ambiente, comprovando a tese de Sampaio (1987), de que o indígena recorria, constantemente, a elementos de seu ambiente para nomear os acidentes físicos e humanos de seu convívio. Nesse sentido, o ambiente físico funciona como a principal motivação do processo de denominação toponímica em que o nome confunde-se, muitas vezes, com o próprio acidente nomeado. 


\subsection{Quanto às taxonomias}

Quanto às taxonomias, convém observar que muitos dos topônimos do corpus podem ter mais de um significado ou têm significado controverso na bibliografia (cf. 5.4). Por conta disso, na classificação taxonômica incluímos em alguns casos o mesmo topônimo em mais de uma categoria, de modo que a soma das ocorrências quantificadas neste item (234) supera o número total de topônimos do corpus (195).

Observamos que a categoria mais produtiva nas três regiões foi a dos fitotopônimos, totalizando um número de 51 termos na região de Aquidauana, $52 \mathrm{em}$ Corumbá e 13 no município de Miranda. A segunda categoria mais produtiva foi a dos zootopônimos, com um número de 24 termos em Aquidauana, 19 em Corumbá e 09 em Miranda.

Ao analisarmos a proporção dos topônimos das diferentes taxonomias observamos a grande incidência de fitotopônimos que totalizam um número de 116 topônimos dentre os 195 analisados. Esse índice comprova a influência da vegetação no processo de designação dos topônimos que nomeiam as regiões analisadas.

Comprovamos também que grande parte desses fitotopônimos refere-se a palmeiras e plantas ornamentais, como é o caso dos designativos: bocaiúva, babaçu, carandá, bacuri e caraguatá, que designam palmeiras ou plantas do gênero das palmas com frutos e seivas utilizados para enfeite e confecção de materiais indígenas.

Todas essas espécies vegetais próprias do cerrado costumam apresentar como características marcantes os troncos e galhos retorcidos, como é o caso do angico e da mangaba, sendo a última delas o nome de uma fazenda do município de Corumbá.

Outra fonte de motivação toponímica também muito presente nessas regiões são as árvores frutíferas, que remetem, de certa forma, não só à importância da alimentação na vida do homem, mas também ao hábito do cultivo dessas árvores como forma de garantir o sustento de muitos povos indígenas que habitaram e habitam essa região. Como exemplo desses topônimos, podemos citar o acaiá, conhecido como cajá - uma designação para o fruto da cajazeira -, fruto bastante conhecido na região; o jatobá, árvore de casca grossa e de frutos comestíveis e do qual se extrai resina; e o jenipapo, fruto do jenipapeiro muito utilizado para se fazer compotas, doces e xaropes e do qual os indígenas extraem uma tinta preta que utilizam em artesanatos e pintura corporal. Essas e muitas outras espécies vegetais, abundantes na região, deram origem a inúmeros designativos para rios, córregos, morros e fazendas do município de Aquidauana, Corumbá e Miranda.

Também fazem parte da vegetação do Pantanal sul-mato-grossense plantas próprias de regiões alagadiças, como é o caso do aguapé, conhecido como vitória-régia e algumas espécies mais resistentes como o buriti, a embaúba, o carandá, bem como outras variedades de coqueiros bastante comuns nessa região, que conseguem sobreviver e fortalecer-se nesse espaço, formando imensos aglomerados.

A segunda categoria mais produtiva é a dos zootopônimos, totalizando um número de 52 topônimos. Observamos que as espécies comuns na fauna local funcionam como a segunda fonte mais produtiva de motivação toponímica. Como exemplos desses designativos, aparecem em nossos dados os topônimos: jacaré, sucuri, jacutinga, curicaca, jaguaretê, anhuma e tuiuiú, espécies comuns nas matas, córregos e alagados da região. $\mathrm{O}$ último desses designativos, o tuiuiú, também conhecido como a cegonha do Pantanal e ave símbolo dessa região, é definido por Taunay (1868, p. 93) em seus relatos de viagem como "a maior das aves ribeirinhas, todo branco com uma coleira vermelha, bico longo e tubulado, que se nutre de peixe e anda no lodo das bordas dos rios".

Após os zootopônimos, os hidrotopônimos, com um número de 16 topônimos ocupam um lugar bastante significativo nesse processo de nomeação. $\mathrm{O}$ grande número de 
córregos, rios, corixos e alagados, próprios do bioma Pantanal, justificam essa grande influência de designativos relacionados à água. Como exemplos desses topônimos, podemos citar os designativos: Aquidauana, caranday, guanabara, lalima, Paraguai, Piauí e Piracicaba que nomeiam rios, fazendas e córregos das regiões analisadas. É interessante observar que, principalmente nos nomes de origem kadiwéu, como é o caso de Aquidauana e lalima, o significado dos topônimos em sua maioria remete à água. Não encontramos, porém, registros que relacionem as características dos acidentes ao nome que recebem, ou seja, não obstante o significado original de Aquidauana, "rio estreito", aparentemente, não há registros de literaturas que descrevam tal característica desse rio. Tampouco lalima, que significa "sumidouro", termo definido por Sampaio (1901, p. 58), como "curso subterrâneo das águas do rio através de rochas calcáreas", aparece em registros escritos como um rio ou córrego com essa característica.

Quanto aos hidrotopônimos de origem tupi e guarani que fazem parte de nossos dados, podemos constatar que, geralmente, essa formação se faz com a justaposição do termo água $-y / i$ a uma base de origem indígena que, por sua vez, já possui um significado próprio. Nesse sentido, os dois termos se juntam e um passa a ser parte do outro, como é o caso de Piaui, Paraguai e caranday, que significam "rio do piau", "rio dos papagaios" e "rio dos carandás", respectivamente.

Bastante próximo dos hidrotopônimos em número de ocorrências, aparecem, nessa cadeia de motivação toponímica, os etnotopônimos que totalizam um número de 13 topônimos e os ergotopônimos, com um total de 12 termos. Relacionados às etnias indígenas, os etnotopônimos designam 6 acidentes da região de Aquidauana, 6 em Corumbá e 1 em Miranda. O fato se justifica em função do grande número de aldeias existentes na região, embora devamos destacar que muitas dessas etnias já foram extintas ou juntaram-se a outras sendo absorvidas por elas, como é o caso dos kinikinaos que, conforme apontamos ao falar da ocupação indígena em Miranda e Aquidauana, juntaramse às aldeias terenas desses municípios. Como exemplos desses topônimos, constam em nossos dados, os topônimos: araras, caeté, carajá e guarani. Etnias já extintas ou que não residem mais na região, mas que participaram efetivamente do processo de criação e desenvolvimento do estado de Mato Grosso do Sul, como é o caso dos guaranis, os indígenas mais explorados como mão de obra no ciclo da mineração.

A respeito da etimologia dos etnotopônimos supracitados, originam-se respectivamente do tupi e do guarani, pois Tibiriçá (1984, p. 65) define o nome tupi arara apenas como uma "ave", Cunha (1998, p. 61) apresenta arara como uma variação de araráarara- arâra, "nome comum a diversas aves de grande porte da família dos psitacídeos", ao passo que Houaiss e Vilar (2001) acrescentam novas acepções às outras já apresentadas, definindo este termo como "indígenas pertencentes ao grupo dos araras, ou língua da família linguística caribe, falada pelos araras". Quanto ao etnotopônimo de origem tupi, caeté, de acordo com Tibiriçá (1984, p. 75), este termo é proveniente de caaeté, "floresta", porém, o autor também assinala a forma caaetê, "tribo indígena inimiga dos portugueses, por incitação dos franceses".

O topônimo tupi carajá, é definido por Tibiriçá (1984, p. 82) como "uma variedade de mono grande, mas também pode ser o nome de uma tribo indígena da Ilha do Bananal". Segundo o dicionário Houaiss e Vilar (2001), este termo nomeia o "indígena pertencente ao grupo ou subgrupo dos carajás, família linguística do tronco macro-jê". Já o topônimo guarani apresenta certa divergência quanto à sua etimologia, uma vez que este topônimo é apontado por Sampaio (1901) e Tibiriçá (1984) como um termo de origem tupi. Entretanto, o dicionário Houaiss e Vilar (2001) aponta este nome como sendo de origem guarani e o define de acordo com três acepções: "o indígena pertencente ao grupo dos guaranis; grupo indígena que habita Mato Grosso do Sul, Rio de Janeiro ao Rio Grande do Sul, onde se 
divide nos subgrupos caiouá, embiá e nhandeva", ou ainda, "a língua da família linguística tupi-guarani, falada pelos guaranis". Guasche Ortiz (1996) e Assis (2008) também apontam este termo como originado do guarani e apresentam a mesma definição dada pelo dicionário Houaiss e Vilar.

É interessante destacar também a referência ao topônimo cabloco que, embora não designe nenhuma etnia indígena em particular, é apresentado nos dicionários consultados como o índio manso e catequizado pelos jesuítas, exatamente como aconteceu com muitos indígenas, principalmente os tupis e guaranis no processo de povoamento do Estado.

$\mathrm{Na}$ escala de motivação dos acidentes físicos e humanos desses três municípios aparecem os litotopônimos com 10 designativos, os dimensiotopônimos com 9 ocorrências, os eco, os mito e os geotopônimos com 3, os coro, pólio e animotopônimos com 2 designativos e, em último lugar, aparecem os soma e hagiotopônimos com apenas 1 designativo.

\subsection{Quanto à origem}

Quanto à etimologia dos topônimos, pudemos constatar o predomínio de termos de origem tupi, seguidos de maneira bastante próxima dos termos apresentados como tupi e também como guarani. No caso dos termos tupis, registramos um total de 28 topônimos em Aquidauana, 33 em Corumbá e 7 em Miranda. Quanto aos designativos de origem controversa, ou seja, tupi/guarani, registramos 26 termos em Aquidauana, 30 em Corumbá e 9 em Miranda. O número de topônimos de origem kadiwéu também é bastante representativo, totalizando um número de 14 ocorrências: 4 em Aquidauana, 4 em Corumbá e 6 em Miranda. Já a respeito dos nomes de origem guarani e terena, o número de topônimos comprovados foi bastante reduzido, totalizando um número de 3 topônimos de origem guarani, sendo encontrados 2 em Aquidauana, 1 em Corumbá e nenhuma ocorrência no município de Miranda. Os designativos de origem terena totalizaram 4 topônimos de nosso corpus: 1 em Aquidauana, 2 em Corumbá e 1 em Miranda.

De acordo com o índice percentual dessas etimologias, os designativos de origem tupi representam $42 \%$ de nosso corpus, seguido de $41 \%$ dos termos que apresentam duas indicações quanto à sua etimologia, como é o caso dos topônimos classificados como tupi e também como guarani nos diferentes dicionários consultados.

Essa duplicidade de registro de etimologias explica-se pelo fato de o tupi e do guarani serem línguas bastante próximas, procedentes de um mesmo tronco linguístico: o tupi. A respeito dessa semelhança, Sampaio (1901, p. 19-20) ressalta que, segundo apontamentos de Couto Magalhães (1876), o tupi e o guarani se comparam ao português e ao castelhano em grau de semelhança ou, ainda, que essas línguas são na verdade uma só, falada em dois períodos diversos da história: o tupi em uma época mais primitiva e o guarani, em um período mais desenvolvido. Nesse sentido, dado o fato de não ser possível determinar com exatidão uma única definição etimológica para esses nomes, optamos por registrar as duas origens apresentadas nos dicionários tupis e guaranis.

$\mathrm{O}$ alto índice de topônimos de origem tupi se justifica pela grande propagação dessa língua no período de colonização do país e pela necessidade da criação de uma língua única que facilitasse a catequização dos indígenas e, consequentemente, maior domínio sobre eles. Assim, segundo Sampaio (1901, p. 14), "fazia-se a conquista tendo por vehiculo a própria língua dos vencidos, que era a língua da multidão". Quanto à influência dessa língua no processo de escolha dos topônimos, o autor destaca que as regiões recémdescobertas ou que ainda estavam sendo desbravadas recebiam um nome de origem tupi, nome este que se perpetuou ao longo do tempo, mesmo que nessa região jamais houvesse habitado uma tribo de etnia tupi, como é o caso de nossos topônimos, pois, embora não 
haja registro de ocupação de nenhuma etnia tupi ou guarani na região por nós estudada, registra-se um percentual de cerca de $83 \%$ de termos dessas procedências, principalmente na designação dos acidentes de natureza física.

Quanto aos topônimos de origem guarani, estes se devem ao intenso processo de exploração de minérios e também às atividades agropecuárias mobilizadas pelo intenso movimento das bandeiras que capturavam esses indígenas e os transportavam para sua utilização como mão de obra barata, o que provocou a quase destruição de muitas aldeias guaranis.

Embora correspondam a um número consideravelmente menor na designação dos acidentes dessa região, 9\% de nosso corpus é composto por topônimos de origem kadiwéu, o que nos permite destacar a influência dessa etnia na toponímia da região, principalmente nos designativos de acidentes físicos como rios e córregos.

Comprovando a tese de Taunay (1868), que declara que quase todos os nomes de rios da região de Miranda são de origem guaicuru, registramos um maior número de termos dessa origem no município de Miranda; a diferença, porém, é bem pequena em relação aos municípios de Aquidauana e Corumbá. Estes topônimos somam um total de 10 ocorrências, das quais destacamos como nomes de origem kadiwéu: Aquidauana, Betione, Chapena, Lalimagadi, Nabileque, Naitaka, Naxedaxe, Nioaque, Taboco, Xatelodo.

Além dessas ocorrências, identificamos em nossos designativos dois topônimos originados da família caribe:

- Córrego Tarumã - topônimo apontado por Tibiriçá (1984), Cunha (1998) e Houaiss e Vilar (2001) como um termo de origem tupi. Tibiriçá (1984, p. 179) define este termo como "uma planta da família das verbenáceas", porém, de acordo com esse autor, tarumã é "o nome de uma extinta tribo da nação caribe", sendo, portanto, esta a sua verdadeira etimologia (TIBIRIÇÁ, 1997, p.146). Cunha (1998, p. 284) aponta a mesma definição dada por Tibiriçá (1984).

- Fazenda Tuiuiu - que de acordo com o dicionário Houaiss e Vilar (2001) é um termo de origem controversa, pois, "segundo JM, provém do tupi tиyи'yu, mas, para Nascentes, o topônimo vem do Caribe teieiu”. Quanto à definição, este dicionário aponta tuiuiú como "o mesmo que jaburu ou cabeça-seca".

Foi identificado também um topônimo de origem bororo:

- Sítio Tarigara - topônimo apontado por Drumond (1965) e Tibiriçá (1997) como um termo de origem bororo.

De acordo como Drumond (1965, p. 104), o termo tarigara é "o nome próprio de um ser fabuloso, gênio que sai da água". Porém, segundo Rondon (1948, apud DRUMOND, 1965, p. 104), este termo é o designativo do "peixe tuvira".

Acreditamos que a presença desses designativos se deve ao processo de povoamento do Estado e às diversas etnias existentes no país no período de descobrimento e de colonização, uma vez que não encontramos registros dessas etnias na região analisada.

Quanto aos designativos de origem terena, somaram apenas $2 \%$ de nossos dados, com um número de 4 topônimos, embora existam cerca de seis aldeias dessa etnia na região. Acreditamos que esse baixo nível se deve à dificuldade de comprovarmos com exatidão a procedência desses termos, devido à indisponibilidade de dicionários específicos dessa língua. Dessa forma, nossa definição da etimologia desses designativos foi 
feita por meio de artigos, glossários e literaturas que estavam mais voltadas para as questões culturais dessa etnia do que propriamente linguísticas.

Sobre os topônimos de origem terena encontrados em nossos dados destacamos:

- Aquidabã - topônimo apontado por Tibiriçá (1997, p. 21) como um termo de origem terena. De acordo com o autor, este termo nomeia "uma numerosa nação indígena que ocupou grande parte do estado de Mato Grosso do Sul e, atualmente, está confinada em pequenos redutos nos municípios de Aquidauana e Miranda".

- Chané - topônimo de origem terena definido por Ladeira (2001, p. 08) como "o grupo social dominante na estrutura social terena; os terenas propriamente ditos". A respeito deste termo, Taunay apresenta algumas considerações, embora não aponte uma definição exata. A princípio, o autor advoga que "os chanés subdividem-se em quatro ramificações: os terenas [...], os laianas, os quiniquinaos e os guanás ou choronós, de entre todos, os mais doces e civilizados" (TAUNAY, 1868, p. 111). Depois, aponta que "no districto de Miranda conhecem-se todos os índios chanés por guanás. Entretanto, perguntando eu, certo dia, a um terena se elle era guaná": "guaná não, chané ou terena, na verdade" (TAUNAY, 1868, p. 128).

Pelo exposto podemos perceber que, em um primeiro momento, chané corresponderia a uma família linguística, porém de acordo com a segunda afirmação de Taunay, este termo corresponde a uma segunda denominação dada à etnia terena.

- Aquidauana - topônimo que provoca muitas discordâncias quanto à sua etimologia. Segundo Tibiriçá (1997, p.21), é um termo de origem terena que nomeia o rio e uma cidade de Mato Grosso do Sul.

De acordo com Robba (1992, apud SOUZA, 2006, p. 9), "alguns autores advogam que o nome Aquidauana, conforme a toponímia tupi-guarani e dos índios guaicurus, quer dizer: $a c$, que significa "grande", $d a$, que significa "lugar" e oana, que corresponde a "araras"; portanto, a definição literal seria "lugar das araras grandes".

Entretanto, conforme Souza (2006, p. 9), “o que se percebe é que os kadiwéus emprestaram sua língua para originar o nome da cidade, na verdade, do rio. Entretanto, não se refere às "araras grandes", e sim a "rio estreito ou pequeno".

Dessa forma, comungando com a definição de Souza, o dicionário da língua kadiwéu organizado por Griffiths (2002, p. 13) afirma que Aquidauana provém do termo kadiwéu- Akidawaani, que significa "rio estreito".

Outro termo que também apresenta essa divergência e duplicidade quanto à sua etimologia é o topônimo nioaque (apresentado anteriormente), que é classificado como de origem terena e kadiwéu ao mesmo tempo, de acordo com diferentes dicionários consultados.

\subsection{Quanto ao significado dos topônimos}

Quanto ao significado dos topônimos registrados, convém destacar que a definição apontada influencia diretamente a classificação taxonômica do topônimo. Dessa forma, muitos de nossos topônimos foram incluídos em mais de uma categoria, pois os dicionários 
indicavam diversos significados. Como exemplo desses termos, temos o córrego araras, localizado nos municípios de Aquidauana e Corumbá.

De acordo com os dicionários consultados, este termo possui três significados e, consequentemente, três classificações. Em uma primeira definição, este nome designa "uma ave de grande porte", o que permite sua classificação como zootopônimo. Em uma segunda definição, porém, nomeia "os indígenas pertencentes à etnia araras", o que o classifica como etnotopônimo. Ainda, em uma terceira definição, designa "a armação de madeira ou metal onde se penduram roupas", o que o caracteriza como ergotopônimo, definição esta, que acreditamos ter sido dada após a povoação dos locais pesquisados, mais por influência do homem branco, do que do próprio indígena.

Constatamos que a maioria dos termos apresentados encontra-se ligada a seus designativos por uma razão mais histórica e cultural do que propriamente física, fato que comprova a tese de Sapir (1969) de que a linguagem é mecanismo que o homem utiliza para exteriorizar sua relação com o meio, relacionado aos aspectos físicos, sociais ou culturais. Um exemplo disso são os designativos de origem kadiwéu: nioaque, nabileque $e$ naitaka.

O primeiro deles se refere ao nome de um rio da região de Corumbá que, em seu significado original, significa "ombro ou clavícula quebrada" e está relacionado a uma história kadiwéu que conta que um de seus guerreiros teve seu ombro ou clavícula quebrada à beira desse rio, o que motivou a designação desse acidente.

O segundo, nabileque, que significa "barro escorregadio", é explicado por Souza (2006, p. 9) como um nome relacionado à época em que os kadiwéus iam vender seus produtos às margens do rio Paraguai, enquanto as mulheres brincavam no barro escorregadio da margem desse rio.

Quanto ao topônimo naitaka, Souza (2006, p. 9) indica que esse nome está relacionado ao fato de que esse rio desaparece no período da seca passando, devido a isso, por "rio mentiroso ou lugar da mentira".

Outro exemplo de motivação toponímica mais relacionada à história do que a característica do acidente é o topônimo guarani Paraguai, que nomeava primeiramente um rio e depois passou a designar um país. Segundo Gubetich (1951, p.13), o significado desse topônimo pode ser explicado em três segmentos, pará, que significa "mar"; gua, que quer dizer "origem"; e $y$, que significa "rio". Dessa forma, esse termo pode ser definido como "rio que origina um mar". Ora, se levarmos em consideração a designação do rio, o significado desse termo pode ser bem aceito; porém, se pensarmos nessa designação para o país, o mesmo não acontece, pois não existe mar no Paraguai.

No entanto, posteriormente, esse raciocínio é esclarecido por Gonzalez (1993, p. 71-72), que defende a ideia de que a tradução correta do termo paraguay seria "rios de los moradores del mar", referindo-se ao povo guarani que habitava os arredores desse rio e o dominava em boa parte, pois navegavam pelo oceano atlântico desde abacia do Prata até o mar do Caribe.

Os mitos também se convertem em grandes fontes de motivação toponímica, como é o caso dos designativos guaranis: jasy, tupaci e pombeiro. Segundo Assis (2008, p. 107), jasyjatereé "um ser mitológico, pequeno e de cabelos dourados, Senhor da sesta e possuidor de uma varinha mágica, que protege a erva feiticeira das abelhas". O topônimo tupaci, do guarani tupasy, relaciona-se não à criatura mitológica propriamente dita, mas a um ser da crença cristã, já que significa "Mãe de Deus, Nossa Senhora, Virgem Maria" (p. 393). Quanto ao topônimo pombeiro, do guarani pombero é "um ser mitológico considerado o ente protetor dos pássaros, que pode ajudar ou prejudicar as pessoas se estas lhe oferecerem fumo ou algum alimento" (p. 309). 
O topônimo iara também é um exemplo de motivação relacionada ao meio cultural. Esse termo tupi/guarani designa a "mãe das águas" e representa um ser mitológico do universo indígena, "Uma espécie de sereia que seduz os homens com seu canto e faz com que estes se percam no mar".

Assim como os topônimos apontados acima, muitos outros termos relacionam-se a seus designativos por razões mais culturais e sociais do que físicas, uma vez que grande parte dos designativos de acidentes físicos e humanos dessa região está mais relacionada à vida e à cultura dos povos que habitaram e participaram efetivamente do processo de desenvolvimento desse território. Sendo assim, só podemos recuperar a motivação toponímica desses nomes se recorrermos à história devida desse povo, num determinado momento de sua existência, o que se torna quase sempre impossível, dadas a escassez de documentos históricos que tragam esses registros, a extinção de muitas dessas etnias indígenas, bem como as constantes deturpações e modificações desses topônimos no decorrer do tempo. Essas questões reforçam a importância de se tentar recuperar o significado original desses termos.

\section{Considerações finais}

Conforme mencionamos na introdução deste trabalho, nosso objetivo geral consistiu na realização de um estudo lexical dos nomes de origem indígena que designam os acidentes físicos e humanos presentes na zona rural das regiões de Aquidauana, Corumbá e Miranda, no estado de Mato Grosso do Sul. Foi dada, também, atenção especial à classificação taxonômica e à análise desses designativos de modo a apresentar seus significados, etimologias e uma provável motivação toponímica que justificasse a escolha desses nomes.

Consideramos como principal hipótese de trabalho o fato de que o grande número de aldeias existentes nessa região influenciou diretamente a escolha dos topônimos, o que justifica o alto índice de nomes indígenas em nossos designativos. Verificamos, entretanto, que esse elevado número de topônimos indígenas relaciona-se mais ao processo de colonização do estado e ao movimento dos bandeirantes nesse período de descoberta, exploração e povoamento, do que à proximidade com as etnias da região. Isso se comprova na constatação de que $83 \%$ de nossos termos são de origem tupi e tupi-guarani, não obstante o registro das etnias guató, kamba, kinikinau e terena que ocupam esse território. Acreditamos que a ausência de registro de topônimos originados dessas etnias se deve ao caráter político e desinteresse governamental na divulgação de documentos e registros históricos que comprovem a presença desses povos no processo de povoamento do estado. Sendo assim, não encontramos designativos originados das três primeiras etnias em nossos dados; aparecem apenas quatro topônimos de origem terena e 14 de origem kadiwéu (estes últimos, embora não habitem em nenhum dos três municípios estudados, localizam-se bem próximos territorialmente.)

A hipótese de que esses topônimos passaram por um processo de renomeação, como acreditávamos a princípio, não pôde ser comprovada. Para tanto, teríamos que ter registros que comprovassem essa alteração de nome, o que significaria estudar o termo de uma perspectiva diacrônica e não sincrônica. Verificamos, porém, que esses nomes passaram por um processo de alteração gráfica, fonética e semântica, o que deu origem às formas variantes desses topônimos e aos inúmeros significados apontados para um mesmo termo. Esse fato acabou por influenciar a classificação taxonômica desses dados, originando o registro de duas ou mais origens para um mesmo nome, como é o caso dos 65 topônimos classificados, a partir das diferentes obras consultadas, como tupi e também como guarani, bem como de outros topônimos apontados nos dicionários como originados 
de línguas e até de famílias diferentes, como é o caso do topônimo Aquidauana, registrado como kadiwéu, terena e tupi, de acordo com diferentes autores.

Constatamos que, aparentemente, esse processo de alteração e surgimento de novos termos, como já apontamos, deu origem também aos topônimos híbridos, em particular aos híbridos indígena-português, que constituem 31 de nossos termos.

Confirmamos ainda que o princípio básico da nomeação dos acidentes físicos e humanos dessa região consiste, acima de tudo, na relação de proximidade entre o homem e o meio, sendo ele quase sempre físico, como é o caso dos designativos relacionados aos elementos do ambiente, como relevo, formações do solo, cursos de água e, em especial, flora e fauna. Essa constatação justifica-se pela existência de 116 ocorrências de fitotopônimos e de 52 ocorrências de zootopônimos. Convém destacar, porém, que os aspectos sociais e culturais das etnias indígenas também influenciaram diretamente o ato da denominação dos acidentes físicos e humanos dessa região. Isso se comprovou especialmente nos topônimos relacionados tanto a elementos étnicos e materiais dessas culturas, como é o caso dos etnotopônimos e ergotopônimos, que totalizaram um número de 25 termos, como também aos seus elementos religiosos e míticos próprios, como os mitotopônimos e hagiotopônimos.

Evidenciamos que, em grande parte dos topônimos, a motivação toponímica e também a etimologia só podem ser recuperadas se recorrermos à história, uma vez que muitos desses nomes estão estreitamente vinculados à linguagem oral, ao hábito de contar histórias e aos acontecimentos relacionados à vida e às andanças desses povos.

Essa preocupação histórica e com o relato oral desses povos torna-se ainda mais justificável em relação aos termos de origem terena, já que, em face da inexistência de dicionários dessa língua, esses dados só podem ser identificados por meio de obras sobre essa etnia, conforme o procedimento de nossa pesquisa, ou por meio de um trabalho exaustivo de coleta e entrevista com os próprios falantes.

Acreditamos que propor um estudo lexical dos inúmeros designativos de origem indígena que formaram e solidificaram a toponímia brasileira consiste em, de certa forma, recuperar a memória de nosso país, confrontando os fatos do passado para compreender o presente, analisando-o posteriormente. Essa relação histórica comprova a afirmação de Dick (1990, p. 22): "o nome de lugar exerce, concomitantemente, o papel de uma verdadeira crônica, em que os fatos atuais se projetam no futuro, através da inscrição onomástica".

Nesse sentido, além de servir como fonte de documentação e ponto de partida para pesquisas futuras, nosso trabalho contribuirá para uma recuperação e valorização das línguas e culturas indígenas no processo de formação do nosso idioma e, principalmente, na formação da toponímia brasileira.

\section{REFERÊNCIAS}

ASSIS, C. F. Dicionário Guarani-Português. 2. ed. São Paulo: Edição própria, 2008.

BARBOSA, A. L. Pequeno vocabulário Português-Tupi. Rio de Janeiro: Livraria São José, 1970.

BASÍLIO, M. Formação de classes de palavras no português do Brasil. 2. ed., $2^{\mathrm{a}}$ reimpr. São Paulo: Contexto, 2009.

BASÍLIO, M. Formação de palavras na língua escrita e na língua falada. In: BASÍLIO, M. Teoria lexical. São Paulo: Ática, 2000. p. 81-89. 
BIDERMAN, M. T. C. Teoria Lingüística. Teoria lexical e lingüística computacional. São Paulo: Martins Fontes, 2001.

BORBA, F. S. et al. Dicionário UNESP do português contemporâneo. São Paulo: UNESP, 2004.

BORBA, F. S. Dicionário de usos do português do Brasil. São Paulo: Ática, 2002.

CAMPESTRINI, H.; GUIMARÃES, A. V. História de Mato Grosso do Sul. Campo Grande: Instituto Histórico e Geográfico de Mato Grosso do Sul, 2002.

CARVALHO, N. Empréstimos lingüísticos na língua portuguesa. São Paulo: Cortez, 2009.

CORRÊA FILHO, V. Pantanais matogrossenses: devastamento e ocupação. Rio de Janeiro: Instituto Brasileiro de Geografia e Estatística, 1946.

COSTA, I. B. Processos morfofonológicos na morfologia derivacional. In: ILARI, R. Gramática do português falado. 4. ed. Campinas, SP: Unicamp, 2002.

CRUZ, G. L. Dicionário das plantas úteis do Brasil. Rio de Janeiro: Civilização Brasileira, 1979.

CUNHA, A. G. Dicionário etimológico Nova Fronteira da língua portuguesa. 2. ed. Rio de Janeiro: Nova Fronteira, 1982.

CUNHA, A. G. Dicionário histórico das palavras portuguesas de origem tupi. 4. ed. Brasília: Companhia Melhoramentos; Universidade de Brasília, 1998.

CUNHA, C.; CINTRA, L. L. Nova gramática do português contemporâneo. Rio de Janeiro: Nova Fronteira, 1985.

DIAS, G. Dicionário da língua tupi - chamada língua geral dos indígenas do Brasil. Rio de Janeiro: Livraria São José, 1970.

DICK, M. V. P. A. Toponímia e antroponímia no Brasil. 2. ed. São Paulo: USP, 1990. Coletânea de Estudos.

FERREIRA, A. B. H. Novo dicionário eletrônico Ferreira versão 5.0. Positivo Informática, 2004.

FRANCISCO, C. S; FRANCISCO, M. A. Pequeno dicionário da língua Terena Vemó'U: Dicionário Aruak-Português para I e II graus. Campo Grande, MS: Ruy Barbosa, 1997.

GONZALEZ, N. Geografia del Paraguay. Edición de Homenaje. Asunción: Cuadernos Republicanos, 1993.

GREISER, P. Dicionário Caldas Aulete da língua portuguesa. Editor responsável Paulo Greiser. Rio de Janeiro: Digital, 2007.

GRESSLER, L. A. SWENSSON, L. J. Aspectos históricos do Povoamento e da colonização do Estado de Mato Grosso do Sul: destaque especial ao município de Dourados. Estado, 1988.

GRESSLER, L.A et al.. História do Mato Grosso do Sul. São Paulo: FTD, 2008.

GRIFFITHS, G. Dicionário kadiwéu-português; português-kadiwéu. Cuiabá, MT: Sociedade Internacional de Linguística, 2002.

GUASCH, A. S. J; ORTIZ, D. Diccionario guarani-castellano; castellano-guarani. 13 ed. Asunción: CEPAG, 1996.

GUBETICH, F. H. Geografía del Paraguay. Asunción: Orbis, SACI, 1951. 
HOLANDA, S. B. Monções. São Paulo: Brasiliense, 2000.

HOUAISS, A; VILLAR, M. S. Dicionário eletrônico da língua portuguesa. Rio de Janeiro: Objetiva, 2001.

KATHIB, F. Dicionário cultural da língua portuguesa. 3. ed. São Paulo: Brasiliense, 1972.

MAGALHÃES, C. O selvagem. Rio de Janeiro: Typographia da reforma, 1876.

MENDES, A. Vocabulário amazônico. São Paulo: Sociedade Impressora Brasileira, 1942.

RIO-TORTO, G. M. Morfologia derivacional: Teoria e aplicação ao português. Porto: Editora Porto, 1998.

RODRIGUES, A. D. A composição em tupi. Separata da Revista Logos, nº14: Curitiba, 1951.

RODRIGUES, A. D. Línguas indígenas: 500 anos de descobertas e perdas. Ciência e Cultura, São Paulo, v. 57, n. 2, 2005.

RODRIGUES, A. D. O tupi na geographia nacional. 5. ed. São Paulo: Nacional, 1987.

SAMPAIO, T. O tupi na geographia nacional. São Paulo: Instituto Histórico e Geográphico de São Paulo, 1901.

SAPIR, E. Língua e ambiente. In: RODRIGUES, A. D. Linguística e Ciência. Rio de Janeiro: Acadêmica, 1969. p. 42-62.

SEKI, L. Línguas indígenas do Brasil no limiar do século XXI. Impulso, Piracicaba/SP, v. 12, n. 27, p. 233-256, 2000.

SOLIS FONSECA, G. La gente pasa, los nombres quedan. Introduccion en la Toponímia. Lima: Lengua y Sociedad, 1997.

SOUZA, J. L. A (in)visibilidade dos lugares Kadiwéu: contribuições da Geografia Cultural para o estudo de populações indígenas. In: V Simpósio Nacional e I Simpósio Internacional sobre Espaço e Cultura, NEPEC/UERJ: Rio de Janeiro, 2006.

TAUNAY, A. E. Scenas de viagem-Memória Descriptiva. Rio de Janeiro: Tipografia Americana, 1868.

TAUNAY, A. E. Vocabulário da língua guaná ou chané. Revista Trimensal do Instituto Histórico Geographico e Ethnográfico do Brasil. Tomo XXXVIII: Rio de Janeiro, 1875. Parte Segunda, p.143-162.

TAVARES, M. Toponímia Sul-Mato-Grossense: um caminhar pelas microrregiões de Dourados, de Iguatemi e de Nova Andradina. Dissertação de Mestrado. UFMS: Três Lagoas, 2004.

TIBIRIÇÁ, L. C. Dicionário de topônimos brasileiros de origem tupi. 2. ed. Brasil: Traço, 1997.

TIBIRIÇÁ, L. C. Dicionário guarani-português. Brasil: Traço, 1989.

TIBIRIÇÁ, L. C. Dicionário tupi-português. 2. ed. Brasil: Traço, 1984.

VILELA, M. Filologia e Linguística Portuguesa v. 1, p. 31-50, 1997.

Recebido em outubro de 2011.

Aprovado em outubro de 2012. 